\title{
Editors/translators Foreword
}

\author{
Daniel Bilar • Eric Filiol
}

(C) Springer-Verlag France 2009

Bereishit In the beginning, there was bureaucracy. I had tried to get major AV companies to give me malware samples to study in an academic setting, but to no avail: Liability reasons, and their suggestion-trekking back and forth to their corporate 'clean' room-was unpalatable to me. I like flat hierarchies, so I turned to herm1t. Herm1t runs (singlehandedly, with minimal equipment and funds) the labour of love known as vxheavens (http://vx.netlux.org), a full-spectrum site dedicated to computer viruses. As quid pro quo, I sent him historical papers he sought for his collection. One title, though, seemed out of reach: A German 1980 MSc thesis by some fellow named Juergen Kraus.

A hefty Dortmund package arrived late October 2006. I was quite pleased. After almost a year of unsuccessful attempts through US academic institutions' Intra Library Loan program, I had the epiphany to contact the computer science librarian at the University of Dortmund, Peter Kleffmann. He managed to locate the sole remaining public copy of the thesis-adding an air of mystery to this trouvaille, it was found stashed away in a vault. I skimmed the thesis :Over two hundred pages on the topic of self-reproducing programs, yet set on a mechanical typewriter, chockfull with hand-edited mathematical formulae and notation, Siemens assembly and SIMULA code. I could not fend off

\section{Bilar}

Department of Computer Science,

University of New Orleans,

New Orleans, USA

E. Filiol (凶)

ESIEA, Laval,

Laboratoire de virologie et de cryptologie opérationnelles, Laval, France

e-mail: efiliol@wanadoo.fr a feeling of nostalgia (and gratitude for Donald Knuth). I set it aside till Christmas break.

As I worked my way through the thesis over Christmas break 2006, my cursory curiosity gave way to wonderment, then awe, then electricity. I felt as if I had stumbled upon a 10th century manuscript in an Scottish convent, delineating the calculus seven hundred years before Leibnitz and Newton. Aspects of the history of computer virology had to be rewritten and proper due given- what a fortuitous find! I sent a printed snail mail copy off to herm1t in the Ukraine and pondered my next steps.

In early February, Eric Filiol, after having discovered an electronic version of the thesis on vxheavens, proposed to me that we jointly translate the work into English, with Juergen Kraus' permission. After almost two years of translation and editing work, Eric and I are pleased to make the translated MSc thesis On Self-Reproducing Computer Programs-easily $\mathrm{PhD}$ quality at a top notch institution today_available to a wider audience.

Kraus' work can be approached from several perspectives: As a software engineering tour de force; as a scholarly mathematical investigation of the minimal requirements for self-reproducing computer programs, as an example of William Carlos William's musings of what would happen in a world, lit by the imagination. It may also be read, as the author suggests, as an expression of the scientific "Zeitgeist" of the late 1970s: With the advent of powerful computer systems (like the IBM 360 series) hooked up to networks (US DoD's ARPANET), the spirit of space exploration still fresh and diffuse fears of computers taking over the world popping up in science fiction themes (movies like Colossus), the question Kraus alluded to seems not too farfetched: Could one identify complex structures within computer systems? Moreover, could these structures evolve into something that resembled biological life? Could they even evolve? 
Thus, an insouciant and inquisitive Juergen Kraus set out to study artificial digital life, with self-reproducing computer programs as his object of investigation. He subsequently offered not only proof that self-reproduction is weaker than recursion (LOOP1 programs are sufficient) and clever constructive examples of such programs in several languages, but had them compete for resources-complete with mutations and crossovers and fitness functions-in a digital biotope.

It is instructive to review some historical precedent. Kleene's recursion theorem (1938) is, of course, explicitly acknowledged in the thesis. Kraus and Claus' speculations were anticipated by von Neumann in his 1949 lecture series where he opined that life as a process could be abstracted away from a particular medium. In 1962 at Bell Labs, Victor Vyssotsky, Robert Morris Sr (Morris fils is the father of the 1988 worm) and Douglas McIllroy developed Darwin, where reproducing computer programs (with the help of a centralized umpire) tried to eliminate competing programs. This setup inspired Core Wars in 1984. The first known (so far) self-reproducing program, a so-called quine written in Atlas Autocode, is attributed to Hamisch Dewar at the University of Edinburgh in the 1960s. His work inspired Bratley and Milo's paper on self-reproducing automata in 1972. Kraus' work in 1980 proved, among other things, that arbitrary functions could be added to self-reproducing programs. As such, he implicitly foreshadowed Cohen and Adleman's 1984 computer virus conceptualization, if not their seminal formalization. ${ }^{1}$

In 1994, ecologist Thomas Ray devised a virtual world called Tierra, seeded with one engineered computer program. Its subsequent offspring, subject to evolutionary pressure in their competition for time and memory resources, gave rise to an ecosystem complete with 'organisms', 'parasites' and 'hyperparasites'. Also in 1994, using a genetic programming framework with LISP programs, John Koza studied the spontaneous emergence of self-reproducing computer programs. Starting with a seed of 12 million 'normal' programs whose functions and terminals could recombine, several hundred self-reproducing programs spontaneously emerged, with a calculated probability of $10^{-6}$ to $10^{-9}$. One has to admire the audacity, instincts, scope and prescience of Kraus's artificial life enterprise.

In addition, considering both the history of computer virology in particular, as well as the domain computer science in general, his work has an incomparable, special quality to it.

\footnotetext{
1 As an aside, the earliest occurrence of the term and idea of a computer virus can be traced back not to Cohen (1983), Brunner (1975), or Gerrold (1972) but to Gregory Benford, then at Lawrence Radiation Lab at Livermore), in Venture Magazine of May 1970. In addition, the enterprising Benford concurrently tried to sell the first known AV product Vaccine he devised against the threat he described.
}

Between von Neumann's groundbreaking work on cellular automata self-reproduction and Cohen's formalization of computer viruses, Juergen Kraus addressed existing epistemological lacunae in an particularly masterly way. While Kleene's recursion theorem (at least one of the numerous forms of that deep theorem) contains already the essence of computer virology (and much more; the reader is refer to Raymond Smullyan's Diagonalization and Self-reference) never before did this complex theorem receive any "practical" treatment. Kraus was the first who not only presented such an application, but also illustrated it with many clever practical programs, thus realizing a harmonious synthesis between hard theory and elegant programming. Where von Neumann's approach was-in this context-rather inductive, Kraus's work is deductive. This last point clearly illustrates the European approach to science where mathematical formalism represents the essential theoretical 'seed' scaffolding for subsequent practical application. In this respect, Kraus built a bridge between Kleene's work and Cohen's thesis. Thus, we may definitively claim that computer virology was born on the "old continent" Europe. Why was Kraus' groundbreaking contribution virtually unknown for so long? There were rumors of the German government locking up the thesis to prevent knowledge of viruses from seeping out. The truth proved much more prosaic: Mr Decker, who realized earlier than most the scientific treasure Dortmund harbored, presciently stashed the last copy in a safe to prevent tidy-minded secretaries from throwing it out. $^{2}$

We are extremely honored to give Juergen Kraus and his work his long overdue tribute. We would like to furthermore extend our gratitude to the following people, without whose efforts none of this could have happened. Prof. Volker Claus (now at the University of Stuttgart, among myriads of innovation a co-founder of the German ACM), the modest and farsighted pioneer of computer science in Germany, for inspiring and guiding Juergen Kraus that fateful winter of 1974/1975. We all should be so lucky to find mentors and students like that. The dedicated herm1t, whose boundless curiosity proved infectious (which does not lack a certain poetry, given the subject matter) and whose services to the virology community are greatly appreciated. Mr Peter Kleffmann, without whose persistence the remaining copy would not have been located. Mr Hans Decker, who enthusiastically supported this translation venture and provided the fascinating background history (of which just the surface

\footnotetext{
2 The suppression conjecture is not completely without merit: The US NSA did try to forbid publication of Schneier's Applied Cryptography in the 1990s and in the 1980s, the German Federal Intelligence Services were particularly interested in the power of computer viruses. Pars pro toto, we mention Stoessel and the BND's Rahab project.
} 
was scratched in this foreword). Mr Decker also enabled us to contact Mr Kraus and to obtain the copyright permissions for this translation. Lastly, Mr Juergen Kraus, whom I had the pleasure of meeting at the 25th anniversary of Computer Science at the University of Dortmund in November 2007. He gave a didactically outstanding presentation. I remember recalling wistfully von Hofmannsthal
"Wie wunderbar sind diese Wesen, Die, was nicht deutbar, dennoch deuten, Was nie geschrieben wurde, lesen, Verworrenes beherrschend binden Und Wege noch im Ewig- Dunkeln finden."

We hope you, the readers, will agree. 